\title{
Compressor maintenance supported by tribodiagnostics
}

Zdeněk Aleš, MSc., Ph.D., Martin Pexa, MSc., Ph.D., Bohuslav Peterka, MSc., Ph.D., Martin Holek, MSc.

Department for Quality and Dependability of Machines, Faculty of Engineering, Czech University of Life Sciences Prague

Kamýcká 129, Praha 6 - Suchdol, Czech Republic. E-mail: ales@tf.czu.cz, pexa@tf.czu.cz

Quality product is dependent on reliable and serviceable manufacturing facility, which is influenced by effective and timely performed maintenance, including checking and refilling of lubricants and other vital fluids. For assessing the state of lubricants and parts of manufacturing machinery, it is possible to use a series of analysis including, for example particle counter and particle shape classifier LaserNet Fines-C, flash point, kinematic viscosity, water content, determination of solid particles, wear metals, etc. Each analysis used to assess technical condition of lubricating oil and machine and helps to carry out maintenance at appropriate intervals, which are directly affected by the technical condition. Such maintenance system achieves economic savings over the maintenance performed in a tightly planed and schedule. The paper compares examples of oil analyses of two compressors.

Keywords: wear, maintenance, tribodiagnostics, LaserNet Fines-C

\section{References}

[1] ALEŠ, Z., PEXA, M., 2010: Diagnostika maziv s využitím laserového analyzátoru LASERNET FINES ${ }^{\circledR}$-C, Časopis - Strojirenská technologie, Ročník XIV, zvláštní vydání, Univerzita Jana Evangelisty Purkyně, FVTM, Ústí nad Labem, 2010, s. 8-11. ISSN 1211-4162

[2] HEŘMÁNEK, P., MAŠEK, J., KRÁL, J., 2010: Hydraulické kapaliny v letectví a jejich diagnostika, Časopis - Strojirrenská technologie, Ročník XIV, zvláštní vydání, Univerzita Jana Evangelisty Purkyně, FVTM, Ústí nad Labem, 2010, s. 70-73. ISSN 1211-4162

[3] POŠTA, J.: Provozuschopnost strojů. Česká zemědělská univerzita v Praze, 2. vydání, Praha, 2006. ISBN 80-2130966-0

[4] JEN Y.-M., YIP M.-C., WEI C.-L., SHU G.-C. Prediction of low-cycle contact fatigue life of sleeve-pin-shaft connections under axial and torsional cyclic loading (2007) International Journal of Fatigue, 29 (5), pp. 796-809. ISSN: 0142-1123

[5] AZIMI G., SHAMANIAN M. Effect of silicon content on the microstructure and properties of Fe-Cr-C hardfacing alloys (2009) Journal of Materials Science, pp. 1-8. ISSN: 0022-2461

[6] LIANG Y.-T., CHIOU Y.-C. Tool wear monitoring: An automated system based on multiple cutting force parameters and machine vision technique (2009) Materials Science Forum, 626 627, pp. 5-10. ISSN: 0255-5476

[7] STACHOWIAK G.P., STACHOWIAK G.W., PODSIADLO P. Automated classification of wear particles based on their surface texture and shape features (2008) Tribology International, 41 (1), pp. 34-43. ISSN 0301-679X

[8] WANG J., XING J., CAO L., SU W., GAO Y. Dry sliding wear behavior of Fe3Al alloys prepared by mechanical alloying and plasma activated sintering (2010) Wear, 268 (2-3), pp. 473-480. ISSN 0043-1648

[9] DIMKOVSKI Z., ANDERBERG C., ROSEN B.-G., OHLSSON R., THOMAS T.R. Quantification of the cold worked material inside the deep honing grooves on cylinder liner surfaces and its effect on wear (2009) Wear, 267 (12), pp. 2235-2242. ISSN 0043-1648

[10] CARROLL R.I., BEYNON J.H. Rolling contact fatigue of white etching layer. Part 2. Numerical results (2007) Wear, 262 (9-10), pp. 1267-1273. ISSN 0043-1648

[11] HRABĚ, P., NAVRÁTILOVÁ, M., HERÁK, D., 2010: Vliv některých parametrů testu na abrazivní opotřebení, Časopis - Strojirrenská technologie, Ročník XIV, zvláštní vydání, Univerzita Jana Evangelisty Purkyně, FVTM, Ústí nad Labem, 2010, s. 84-87. ISSN 1211-4162

[12] DOBRÁNSKY, J., KREVEL, R., 2010: Analýza kvality použitého oleja a meranie vibraci hrotového sústruhu SV 18RA, In Strojírenská technologie, Ročník XIV, zvláštní vydání, Univerzita Jana Evangelisty Purkyně, FVTM, Ústí nad Labem, 2010, s. 33-36. ISSN 1211-4162

[13] CHOTĚBORSKÝ, R., HRABĚ, P., MÜLLER, M., SAVKOVÁ, J., JIRKA, M., NAVRÁTILOVÁ, M. : Effect of abrasive particle size on abrasive wear of hardfacing alloys, Research in Agricultural Engineering, Volume 55, Issue 3, 2009, s. 101-113. ISSN: 12129151 
[14] ZIEGLER, J.; HELEBRANT, F.; MARASOVÁ, D.: Technická diagnostika a spolehlivost I Tribodiagnostika, Vysoká škola báňská, Ostrava, 2004. ISBN 80-7078-883-6

[15] ŠAFR, E.: Tribotechnika, SNTL, Praha, 1984.

[16] KREMANOVÁ, B., MÁDL, J., RÁZEK, V., KOUTNÝ, V.: Termooxidační stabilita nových rostlinných řezných olejů a výzkum jejich technologických vlastností, Časopis - Strojírenská technologie. Ročník VIII, Univerzita Jana Evangelisty Purkyně, FVTM, Ústí nad Labem, 2003, s. 21-24. ISSN 1211-4162

[17] LAHUČKÝ, L., MAGA, D., LOPTÁM, P.: Zlepšení tribologických parametrů chemicko-tepelnou úpravou povrchů. Časopis - Strojírenská technologie. Ročník XII, Univerzita Jana Evangelisty Purkyně, FVTM, Ústí nad Labem, 2007, s. 29-33. ISSN 1211-4162

\section{List of standards}

[18] ČSN 65 6062. Ropné výrobky. Stanovení obsahu vody. [s.1.] : [s.n.], 1.1.1983. 12 s.

[19] ČSN 65 6231. Ropné oleje - Kvalitativní zkouška na vodu. [s.1.] : [s.n.], 1.8.2006. 8 s.

[20] ČSN EN ISO 2592. Stanovení bodu vzplanutí a bodu hoření - Metoda otevřeného kelímku podle Clevelanda. [s.1.] : [s.n.], 1.5.2004. $20 \mathrm{~s}$.

[21] ČSN EN ISO 3104. Ropné výrobky - Průhledné a neprůhledné kapaliny - Stanovení kinematické viskozity a výpočet dynamické viskozity. [s.l.] : [s.n.], 1.1.1998. $20 \mathrm{~s}$.

[22] ČSN ISO 4406. Hydraulické kapaliny - Kapaliny - Metoda kódování úrovně znečištění pevnými částicemi. [s.1.] : [s.n.], 1.8.2006. $12 \mathrm{~s}$.

[23] ČSN ISO 760. Stanovení vody - Metoda Karl Fischera - (Všeobecná metoda). [s.1.] : [s.n.], 1.10.1998. 20 s.

Reviews:

Prof. František Holešovský, MSc., Ph.D. Assoc. Prof. Pavel Bach, MSc., Ph.D. 